\title{
Virtual Laboratory in Chemistry - Experimental Study of Understanding, Reproduction and Application of Acquired Knowledge of Subject's Chemical Content
}

\author{
Nataša Rizman Herga', Dejan Dinevski²
}

\author{
${ }^{1}$ OŠ Ormož, Hardek 5, 2270 Ormož, Slovenia, natasa_herga@yahoo.com \\ 2University of Maribor, Faculty of Education, Koroška c. 160, Maribor, Slovenia, dejan.dinevski@uni-mb.si
}

\begin{abstract}
Traditional teaching does not often allow very active involvement of pupils in class. In chemistry and natural sciences in general experimental and laboratory work is one of the most effective methods for acquiring knowledge. Experimental work can also be exercised using virtual world. Virtual laboratory offers some important advantages. Understanding chemistry involves the ability of cognitive comprehension on three levels: the macroscopic level, the symbolic level and the level of particles where the virtual laboratory can be an effective tool. On this basis a didactic experiment was performed in order to verify the effectiveness of virtual laboratory from pupils' knowledge point of view. The experiment involved seventh grade pupils $(\mathrm{N}=38)$. Furthermore, we tried to answer the question whether the learning results of pupils, according to the experimental design of classes using a virtual laboratory, are better than results gained through teaching classical science classes without visualization tools. The research of the didactic experiment carried out on a relatively small, pilot sample of pupils has shown that acquiring knowledge is more effective when using the virtual laboratory instead of classical teaching (in the case when classical approach does not include visualization elements crucial for learning and understanding chemistry).
\end{abstract}

Key words: virtual laboratory, science, chemical and visual literacy, knowledge

\section{Introduction}

In teaching science teachers often proceed from the fact that nature is the best source of information. The basic and at the same time the most effective method in gaining chemistry related knowledge is experimental and laboratory work. Basic science concepts are introduced by experiments. In a dynamic social environment like today's traditional forms of education and training do not suffice. Information and communication technology (ICT) opens up a new world of creativity for students and teachers. The understanding of chemical concepts and processes can be increased if we provide the development of chemical visual literacy. Key elements of chemical visual literacy are perception and the ability to describe changes at the macroscopic level and the correct perception of the natural partition structure of matter at the submicroscopic level. We use molecular and crystal models. In school laboratory experiments can be carried out in a realistic or virtual manner. With virtual experiments the experiments are carried out using computer simulations or animations. One of the advantages of virtual laboratory, among other things, is that it allows the portrayal of matter's model structure which is a prerequisite for proper understanding of the natural partition structure of matter.

\section{Learning science concepts}

Teaching scientific concepts should be firstly based on the observation of a particular science process which means that the natural process is perceived through perception or senses. At the second stage it is necessary to explain the observations with theories based on the partition structure of matter that are at a given time and on a certain level of education scientifically indisputable. At the third level is the understanding of a chemical concept. The submicroscopic level is translated into the appropriate symbols which include chemical symbols, formulas and equations, mathematical equations, different

Received: $11^{\text {th }}$ November 2011; revised $4^{\text {th }}$ January 2012; accepted 3rd March 2012 
schematic and graphical presentations and more. This level permits an easier interpretation of the situation and mutual communication between those who are acquainted with the symbolic language. Science education particularly seen from the symbolic level without integrating it with the previous two, can lead to the creation or strengthening of already established misunderstandings if these symbols are not correctly interpreted and integrated into the existing network of knowledge (Devetak et al., 2009).

In chemistry and natural sciences in general, the experimental and laboratory work is one of the most effective methods for acquiring knowledge. The detection of concept world of matter, phenomena and processes is characteristic for chemistry at the macroscopic level. For interpreting and forecasting we must use the language of the submicroscopic world. While learning chemistry it is important that students understand and can connect concepts on all three conceptual levels (macroscopic, submicroscopic and symbolic) which is difficult for many of them. The gap between the three conceptual levels can be, to the great extent, overcome by the use of visualization elements. Thus the ability to use models in teaching and learning chemistry is among the key chemical elements of visual literacy (Vrtačnik et al., 2003).

\subsection{ICT and science}

In a dynamic social, production and service environment such an environment as today's traditional forms of education and training no longer suffice. Electronic interactive media allows us to take a look at the micro-world of living or inanimate nature, fly between planets of the solar system or take a look at how a real laboratory experiment should be performed in a classroom. Information and communication technology (ICT) opens up a new educational world of creativity for students and teachers. ICT plays an important role in planning lessons and in their management (Grimaldi and Rapuano, 2009). The use of ICT could be divided into two groups: in the first group a computer is used as a tool for finding information, communication and multimedia and in the second group the computer is a scientific tool such as a virtual laboratory, interactive simulation, computer-assisted laboratory work (Šorgo et al., 2007).

The use of computers in science subjects, particularly chemistry, has some specific advantages. Cognitive psychologists assume that the understanding of chemistry includes the ability to think on three levels: the macroscopic level, the symbolic level and the level of particles (Johnstone, 1991). Pupils and students have the most difficulties in understanding the submicroscopic level - the level of particles because it reaches beyond their experience. In these cases the interactive multimedia can be used as an effective tool. Multimedia demonstration of experiments must not replace other methods of work in teaching chemistry. Virtual laboratory can eliminate uninteresting and boring parts of the experiments. It helps students understand higher cognitive levels of analysis, synthesis and evaluation (Kirscher and Huisman, 1998). The use of multimedia and virtual laboratories for teaching chemistry improves teaching because it allows the integration of the three levels of understanding of chemistry, visualization and simulation of processes.

\subsection{Experimental work and virtual laboratory}

In chemistry and natural sciences in general the experimental laboratory work is one of the most effective methods for acquiring knowledge. From a didactic point of view the experimental work is of the utmost importance because it sometimes discontinues the monotonous teaching of theory with practical work. Experimental work can be divided into real and virtual. Classical experimental work is the best known method of practical work and is most commonly used in teaching science and chemistry in elementary school. For students who choose the subject. Experiments in chemistry are a fundamental and predominant form of work. Students train their manual skills, develop the ability to describe chemical changes, learn about physical and chemical properties of matter, develop safety at work abilities in the school laboratory, they strengthen and complement knowledge, abilities and skills, develop an experimental approach as a form of research work.

The experimental work allows them to develop and deepen their science literacy, basics of scientific work, complex thinking and linking theory with practice. As proved, the students want to elevate the frequency of laboratory work covered in traditional classes (Šorgo and Špernjak, 2007).

Virtual laboratory exercises are held in the virtual world. Virtual lab brings many advantages. We can perform dangerous experiments without endangering ourselves or others. Simulations are affordable. Once developed, they can be done at no extra costs as many times as we want. The results are always the same.

The main disadvantage of a virtual laboratory is the alienation from nature and from what is real. Therefore simulations are mostly a good supplement and not a substitute for practical experimental work (Puhek 2009, p. 6-7).

In Table 1 we compare the classical and virtual laboratory. The "+" sign represents the advantages of laboratory, the "-" sign the disadvantage of the same laboratory.

Interactive 3D virtual environments have great educational potential because they enable the active participation of students, research and management of virtual objects. Virtual laboratories reproduce the conditions of a real chemical laboratory and enable learning through an interactive simulation and are a valuable tool for distance learning and lifelong learning of chemistry. Virtual laboratories allow the execution of experiments without teacher's presence; therefore students have a major role in their learning process. Studies have shown that virtual laboratory is an appropriate tool with which chemistry students prepare for practical work (Dalgarno et al., 2010, Georgio et al., 2008, Rajendran et al., 2010).

\subsection{Program Crocodile Clips Chemistry}

Scottish enterprise Crocodile Clips Ltd develops educational software for primary and secondary schools. Crocodile Clips products are recommended by teachers worldwide as an innovative approach to learning. A new generation of educational tools of the same enterprise is called Yenka. Yenka can be used at home or in schools with an interactive blackboard. It is free software as far its purpose is domestic use. 
Table 1: Advantages and disadvantages of classical and virtual laboratory

\begin{tabular}{|l|l|}
\hline Classical experimental work & Virtual laboratory \\
\hline + training manual skills & + learning about the scientific approach to work \\
\hline + learning about the scientific approach to work & + the results are always the same \\
\hline + following instructions & + a large range of chemicals and accessories \\
\hline - preliminary preparation & $\begin{array}{l}\text { + an easy implementation of dangerous, expensive, harmful to } \\
\text { health experiments or experiments in specific conditions }\end{array}$ \\
\hline - dangerous or harmful to health chemicals & + inexpensive \\
\hline - difficult, too long or too expensive experiments & + visualization features are included \\
\hline - there are variations & - alienation from nature and from reality \\
\hline & $\begin{array}{l}\text { - it can be only a supplement and not a replacement of practical } \\
\text { work }\end{array}$ \\
\hline
\end{tabular}

Virtual Chemical Laboratory Crocodile Clips Chemistry is a sophisticated, user-friendly interactive simulation program for teaching and for independent student work. The program provides a clear and simple display of phenomena on the following themes: energy, water and water solutions, alkalis, salts, acids, metals, materials and much more...

They may also use gadgets, glassware and chemicals to compose an experiment by themselves. The program has the ability to modify the already existing experiments.

Students or teachers can adapt the existing experiment by changing different parameters such as temperature, mass, concentration. In the book of elements we find an abundant amount of equipment found in chemical laboratories and more than a hundred different chemicals with which we can also carry out any kind of experiments that are too dangerous for the school laboratory. Animations can be seen on the submicroscopic level with relevant displays of atoms or molecule.

Topics of this program were properly connected to the chemical content that students learn at science in the seventh grade of elementary school.

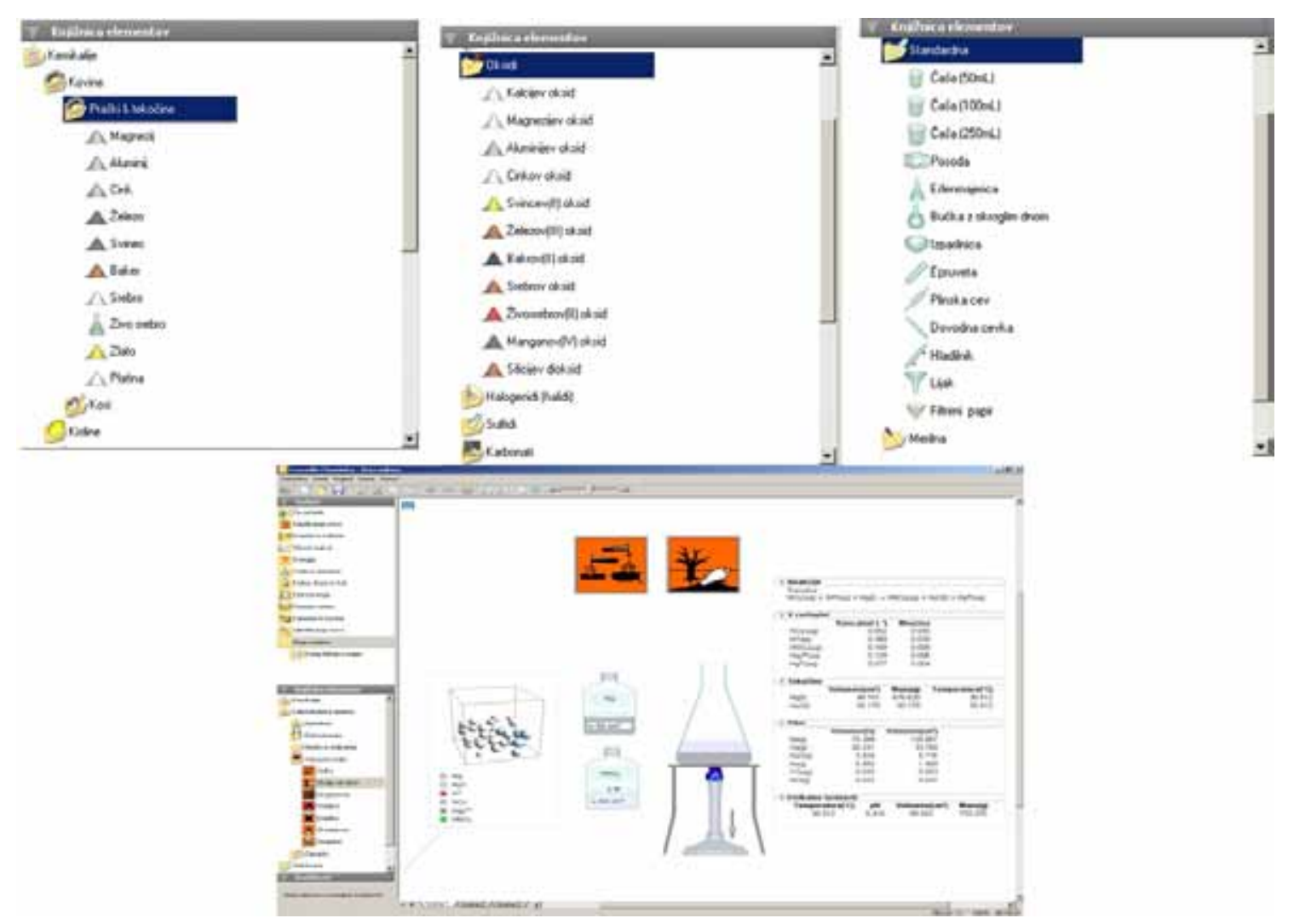

Figure 1: A book of elements featuring selected glassware and chemicals 


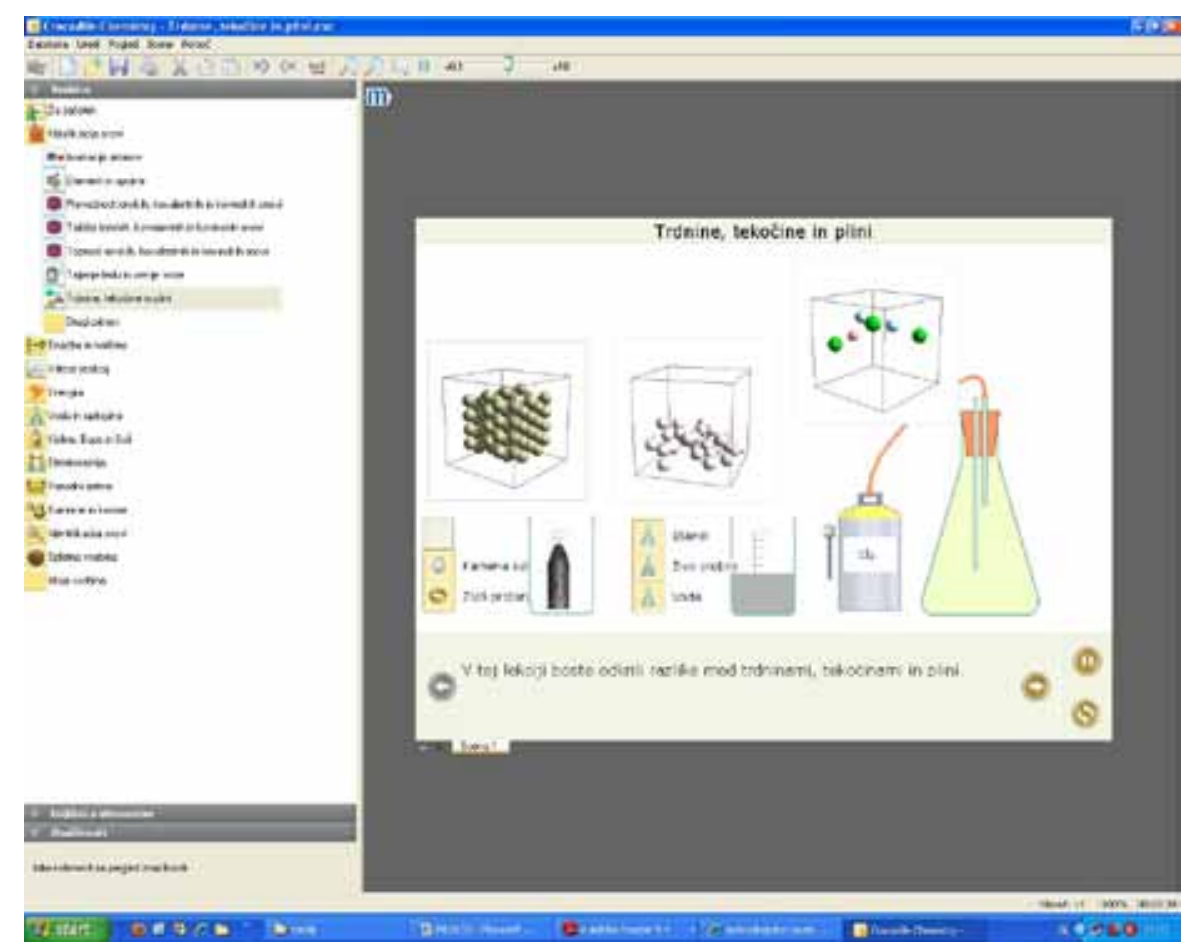

Figure 2: Solid, liquid and gaseous physical state - an example of the content that we used in class with the experimental group.

\section{Methodology}

\subsection{Purpose of the research and methodology}

In this study we wanted to determine the effect of chemistry lessons executed in a virtual laboratory in the seventh class of primary school. To study the impact of lessons performed by a virtual laboratory we used an experimental method of the traditional empirical-analytical educational research. Research was conducted in the experimental (EG) and control (CG) group. In the virtual laboratory classroom we used the program Crocodile Clips Chemistry. Lessons with a virtual laboratory were performed in the experimental group. In the control group the teacher taught according to a conventional teaching approach which is used in the classroom. We were therefore interested in the effect on students' knowledge taught by the lessons carried out with a virtual laboratory. Knowledge is reflected on three levels: reproduction, comprehension and application of knowledge. The educational experiment covered chemical contents:

1. substances, their properties and changes,

2. pure substances and mixtures.

\subsection{Experimental model}

We designed a one factor experiment with two classes as the comparing groups. Research was conducted in the experimental (EG) and the control group (CG). In a virtual laboratory classroom we used the program Crocodile Clips Chemistry.
Virtual laboratory classes were performed in the experimental group. The experimental factor had two modalities:

- teaching science according to the standardized curriculum with the traditional approaches used by a teacher in a classroom; describing changes at the macroscopic level and illustrating the reactions with symbols and formulas (symbolic level) (CG),

- teaching science according to the standardized curriculum where the teacher includes a virtual laboratory in the traditional approach that allows to view changes and processes on the submicroscopic level (EG).

To ensure content validity (thorough identification and verification of actual achievements), we studied the effectiveness of the experiment after teaching students the themes Substances, their properties and changes and Pure substances and mixtures in terms of science knowledge (chemical part), expressed as:

- the total score of numbers on the examination,

- the result of the examination at three levels of Bloom's cognitive taxonomy: knowledge, understanding and application.

\subsection{Defining the sample}

The didactic experiment involved 38 students $(n=38)$ of Primary School Ormož. Students attended the 7th class and were eleven or twelve years old.

A select group of students represents, in the context of statistical hypothesis testing, a simple coincidental sample out of a hypothetical population. 

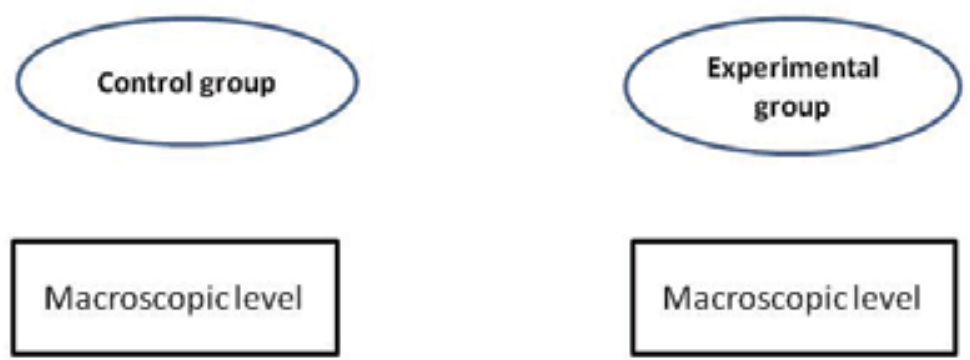

Macroscopiclevel

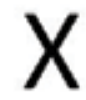

Symboliclevel
Submicroscopic

level

Symboliclevel

Figure 3: Schematic diagram of the implementation of research in the classroom

Table 2: Number $(f)$ and percentage ( $f \%)$ of participating students in the experimental (EG) and control (CG) group.

\begin{tabular}{|l|c|c|}
\hline GROUP & $\mathrm{f}$ & $\mathrm{f} \%$ \\
\hline EG & 20 & 52,6 \\
\hline CG & 18 & 47,4 \\
\hline TOTAL & 38 & 100 \\
\hline
\end{tabular}

\subsection{Data collection procedures}

Data were collected by testing students' knowledge after lessons. Furthermore we carried out a rational and empirical validation of tests. Rational validation is based on assessing the appropriateness of content and design of the test. For empirical validation we used factor analysis solution, namely the percentage of explained variation by the first common factor ( $\%$ ex. var. $\mathrm{F} 1)$. Given that the first factor explains $24.5 \%$ of the variance and is above the limit of the criterion for the lower limit $(20 \%)$, we estimate that the examination is valid. To determine the reliability of the examination we used Cronbach's alpha coefficient $(\alpha=0.832)$. This confirms that it is a reliable instrument for assessing knowledge after the experiment. Objectivity of knowledge testing was provided by detailed instructions. Many questions on the test were closedended question. The results in both groups were evaluated by the same teacher according to the criteria.

In February 2011 we defined the experimental and control group and by that we gained the necessary information prior to the initiation of the experiment. In both groups (EG and CG) we verified the background knowledge with a test.
In March we carried out a didactic experiment that lasted a month. Following the completion of the didactic experiment we wanted to once again test students' knowledge to diagnose their progress on learning and to compare one group to the other. Knowledge testing after the experiment consisted of 14 tasks (42 possible points). The examination had tasks based on three levels of difficulty:

- knowledge testing tasks (17 points),

- understanding testing tasks (12 points),

- application of knowledge testing tasks (13 points).

Performance evaluation was conducted according to criteria and a scale of possible points.

\subsection{Data processing procedures}

The data were processed using the SPSS program, treated at the level of descriptive and inference statistics. We used onefactor analysis of covariance for examining differences in the arithmetic mean of scored points on the knowledge testing after the experiment based on the equivalence of the groups at the beginning.

\section{Results}

Before carrying out the experiment we analyzed the total score on the knowledge testing prior to the experiment.

The assumption of homogeneity of variance, on which the use of the t-test is based, is justified $(\mathrm{F}=0.430, \mathrm{P}=0.516)$.

As shown by the outcome of the t-test according to knowledge before the experiment there were no statistically significant differences $(t=0.749, P=0.635)$ among students. 
Table 3: Results of the t-test of differences in the total score on the knowledge testing among students of the experimental (EG) and control group $(C G)$ group prior to the experiment

\begin{tabular}{|c|c|c|c|c|c|c|c|}
\hline GROUP & $\begin{array}{c}\text { Numerous } \\
\mathrm{n}\end{array}$ & $\begin{array}{c}\text { Arithmetic mean } \\
\bar{x}\end{array}$ & \multicolumn{2}{|c|}{$\begin{array}{c}\text { Standard } \\
\text { deviation }\end{array}$} & \multicolumn{2}{|c|}{$\begin{array}{c}\text { Test of homogeneity } \\
\text { of variances }\end{array}$} & \multicolumn{2}{|c|}{$\begin{array}{c}\text { Test of the arithmetic } \\
\text { mean difference }\end{array}$} \\
\hline EG & 22 & 37,23 & 6,76 & $\mathrm{~F}$ & $\mathrm{P}$ & $\mathrm{t}$ & $\mathrm{P}$ \\
\hline $\mathrm{CG}$ & 17 & 36,18 & 7,68 & 0,430 & 0,516 & 0,749 & 0,635 \\
\hline
\end{tabular}

Table 4: Results of one-factor analysis of covariance of differences between the experimental (EG) and control group (CG) of the total score of the knowledge testing after the experiment as a CRITERION VARIABLE with testing their knowledge prior to the experiment

\begin{tabular}{|c|c|c|c|c|c|c|c|c|c|}
\hline GROUP & $\begin{array}{c}\text { Numerous } \\
\mathrm{n}\end{array}$ & $\begin{array}{c}\text { Arithmetic } \\
\text { mean } \\
\bar{x}\end{array}$ & $\begin{array}{c}\text { Standard } \\
\text { deviation }\end{array}$ & \multicolumn{2}{|c|}{$\begin{array}{c}\text { Test of homogeneity } \\
\text { of variances }\end{array}$} & \multicolumn{2}{|c|}{$\begin{array}{c}\text { Test of homoge- } \\
\text { neity of regres- } \\
\text { sion coefficients }\end{array}$} & \multicolumn{2}{|c|}{$\begin{array}{c}\text { Test of the arithme- } \\
\text { tic mean difference }\end{array}$} \\
\hline EG & 20 & 32,65 & 4,88 & $\mathrm{~F}$ & $\mathrm{P}$ & $\mathrm{F}$ & $\mathrm{P}$ & $\mathrm{F}$ & $\mathrm{P}$ \\
\hline $\mathrm{CG}$ & 17 & 27,29 & 6,79 & 1,706 & 0,200 & 2,003 & 0,166 & 7,718 & 0,009 \\
\hline
\end{tabular}

\subsection{Knowledge after executing the didactical experiment}

After executing the experiment we used a written test for evaluating their knowledge. We analyzed the joint result and the score of all scores achieved on the written test.

Assumptions on the homogeneity of variances $(\mathrm{F}=1.706$ $\mathrm{P}=0.200)$ and on the homogeneity of regression coefficients $(\mathrm{F}=2.003, \mathrm{P}=0.166)$ were eligible.
The difference between the adjusted arithmetic mean of students' test scores in experimental and control group was statistically significant $(\mathrm{F}=7.718, \mathrm{P}=0.009)$

Students in the experimental group $(\bar{x}=32.65)$ were better in knowledge testing after the experiment than students in the control group $(\bar{x}=27.29)$. According to knowledge the experimental group's students who learned about the chemical contents with a virtual laboratory had the advantage over the control group where traditional lessons were carried out.

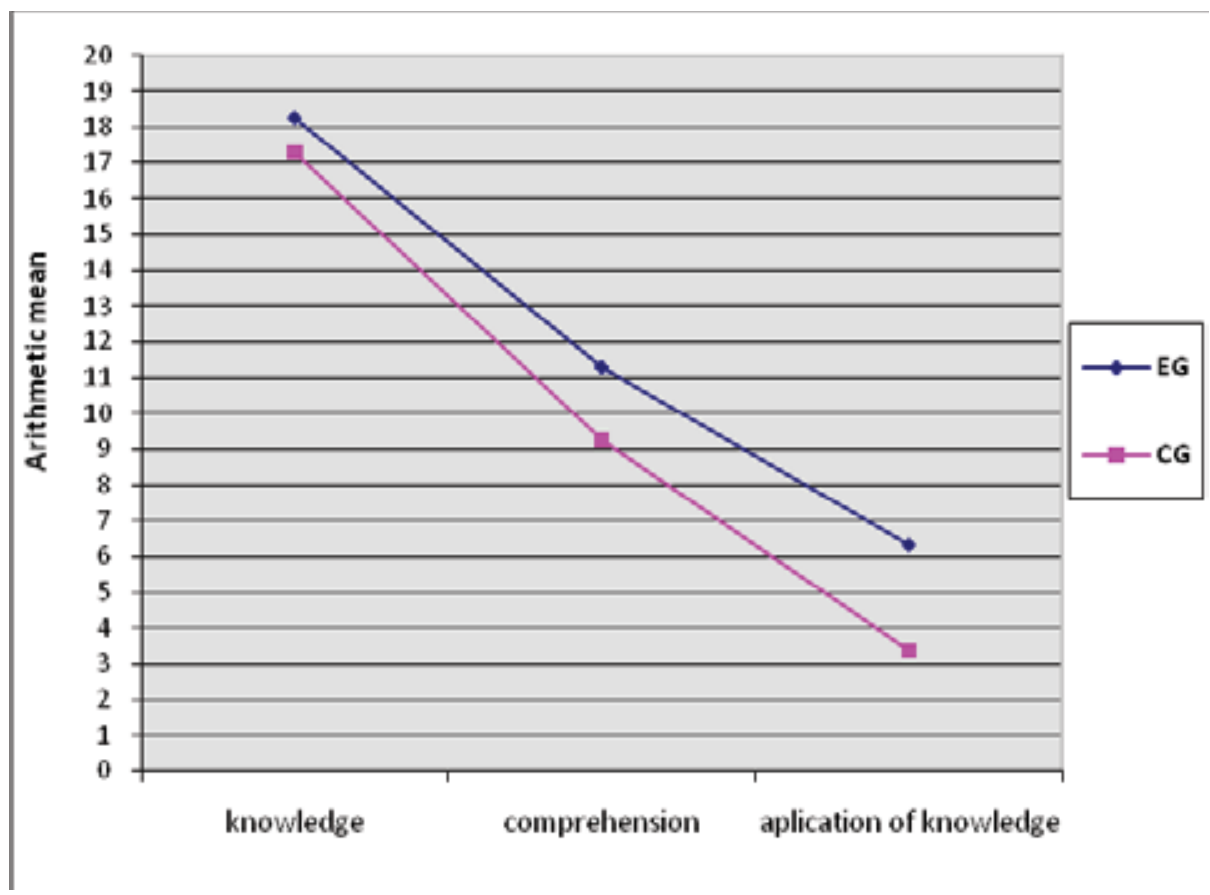

Graph 1: The arithmetic mean of students' acomplishments (EG and CG) on the various levels of tasks testing chemical content after the experiment. 


\subsection{Analysis of differences between experimental and control group on the various levels of knowledge}

Knowledge testing consisted of three levels of tasks according to Bloom's taxonomy of objectives for cognitive area: knowledge, comprehension and application of knowledge. The chart below shows the arithmetic mean of individual levels of knowledge when testing knowledge.

The graphical display shows that the line of the experimental group (EG) is above the line of the control group (CG). The score line of the test decreases because the most tasks required students' knowledge, the number of tasks based on understanding and application of knowledge were smaller in number and the score line does not fall because the students were less successful in these tasks. Students of the experimental group scored more points in all three types of tasks compared to the control group of students. Distinct differences are visible in comprehension and application of knowledge. Results in table 5 show whether the detected differences are statistically significant.

\section{a) Achievements on knowledge testing tasks}

The results show that the assumption of homogeneity of variance is justified $(\mathrm{F}=0.002, \mathrm{P}=0.962)$ as well as the assumption of homogeneity of the level regression coefficients ( $\mathrm{F}=0.915, \mathrm{P}=0.346)$. The difference between the adjusted arithmetic mean of the students' test scores between experimental and control groups was not statistically significant $(F$ $=0.712, \mathrm{P}=0.405)$. Experimental group's students $(\bar{x}=18.25)$ were slightly better than students in the control group $(\bar{x}=$ 17.29) considering knowledge testing after the implementation of the experiment. In the reproduction of knowledge the experimental group students did not have the advantage over the control group students.

b) Achievements on comprehension testing tasks

Assumption of homogeneity of variances $(\mathrm{F}=2.428, \mathrm{P}$ $=0.128)$ and homogeneity level of regression coefficients $(\mathrm{F}=2.012, \mathrm{P}=0.165)$ were eligible. Although there is no statistically significant difference among EG and CG students' knowledge after the experiment, there is a statistically significant difference in solving the tasks that were checking students' understanding ( $\mathrm{F}=6.987, \mathrm{P}=0.012)$. The acquired knowledge of the students who learned the prescribed content in class using the virtual laboratory $(\bar{x}=11.30)$ is statistically better than the control group $(\bar{x}=9.25)$. At the level of concept understanding the students in the experimental group had an advantage over the control group's students.

c) Achievements on application of knowledge testing tasks

Table 5 shows that the assumption of homogeneity of variances of the coefficients $(\mathrm{F}=0.090, \mathrm{P}=0.766)$ and the assumption of homogeneity level of regression coefficients ( $F$ $=1.875, \mathrm{P}=0.180$ ) are justified. Results of the overall F-test show that there is a statistically significant difference between the two adjusted arithmetic means $(\mathrm{F}=26.096, \mathrm{P}=0.000)$. Experimental group's students $(\bar{x}=6.35)$ were exceptionally successful at tasks that required the use of knowledge in comparison to the control group $(\bar{x}=3.76)$. In terms of application

Table 5: Results of one-factor analysis of covariance of differences between the experimental (EG) and control group (CG) in acomplishments with knowledge, comprehension and application of knowledge tasks as a CRITERION VARIABLE with testing their knowledge prior to the experiment

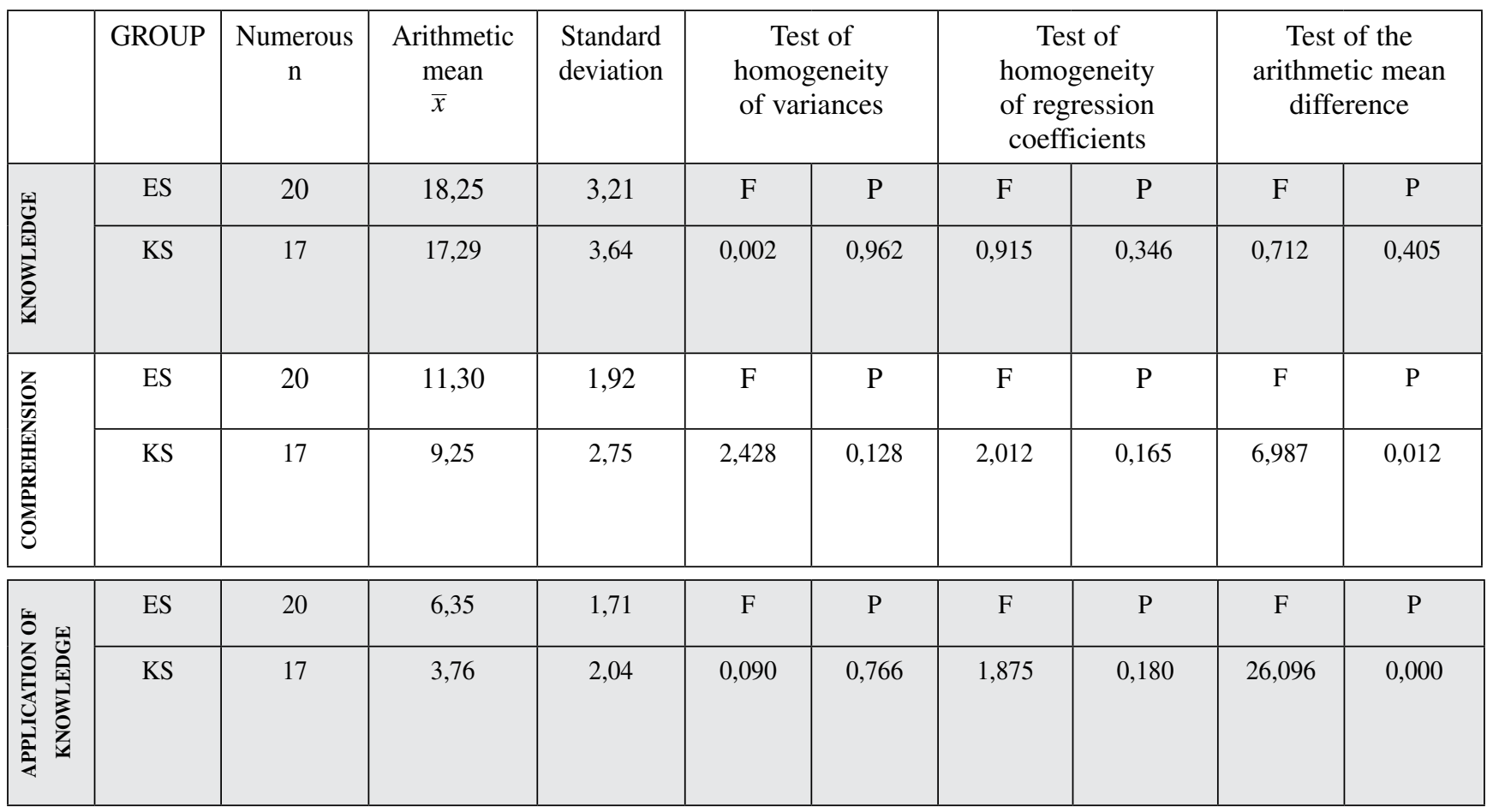


of knowledge the experimental group's students also have the advantage over the control group's students.

\section{Discussion}

The virtual chemical laboratory gives students and teachers potential educational tools that allow them to introduce new strategies to support higher-level skills: communication and information literacy, self-management knowledge skills, problem solving, independent learning, cooperative learning and the like.

In this study we identified statistically positive impacts in the field of chemical content's knowledge of the experimental group. Experimental group's better results may be justified with the use of virtual laboratory. Students of the experimental group were given the explanation of the phenomena at all three levels: the macroscopic level, the symbolic level and submicroscopic level. The gap between the three levels can largely be overcome by the use of visualization elements (Barke and Wirbs, 2002). Students have the most difficulties in understanding the submicroscopic level - the level of particles. This crucial element was experienced by the experimental group by the use of the virtual laboratory. The advantages of using a virtual laboratory were also demonstrated by the research that took place in the study of analytical chemistry (Zimmerer et al., 2003).

Students of the control group were given classes following the well established curriculum with the traditional approach used by a teacher in the classroom. The changes were shown on the macroscopic and symbolic level including the use of ICT. ICT plays an important role in planning lessons and in their management (Grimaldi and Rapuano, 2009) and allows the introduction of more active forms of learning. Using a virtual laboratory represents an upgrade of the traditional teaching (Chin, 1999) and from this point of view experimental group's students had an advantage over the control group's students. Better designed laboratories on the basis of educational theory can lead to better learning outcomes (Abdulwahed and Nagy, 2009). The study on the effectiveness of the virtual laboratory in e-learning (Rajendran et al., 2010) showed that students prefer to learn using computer aided tools comapred to textbooks. The fact that students prefer to use online virtual labs rather than just reading textbooks was confirmed by the study of authors Sun, Lin and Yu from 2008. On the basis of this research the measured better results of students' knowledge of the experimental group were due to the use of virtual laboratory and therefore greater self-initiative of experimental group's students.

By using the virtual laboratory Crocodile Clips Chemistry we presented the experimental group's students changes on the submicroscopic level and so overcame the gap between the three presentation levels in chemistry. However, this program also has its shortcomings that were not important at this level of education. The basic matter constituents are presented in the form of spheres regardless it is a molecule of water or for example a two-atom element. At this point it is important that the teacher chooses the appropriate tool for students out of a multitude of learning tools. She should choose the tool that is adapted for students, their learning style and abilities in accordance with the curriculum. Many laboratories are merely technological substitutes for the real laboratories where we have computer-based demonstrations of experiments. With such laboratories we are losing the basic elements of the science methodology.

\section{Conclusion}

We studied lessons with the virtual laboratory as a method of teaching and learning science. Lessons were carried out using the Crocodile Clips Chemistry program. The program offers a large range of different experiments that can be repeated when consolidating and testing knowledge. We can change reaction conditions and examine the course of the reaction on the submicroscopic level. With this we included visualization elements that are crucial for learning and understanding chemistry. Research has shown that even very successful students in solving mathematical - chemical concepts often do not know how to explain what is happening at the level of particles.

The effectiveness of lessons carried out with a virtual laboratory was examined from knowledge's point of view at three levels: knowledge, comprehension and application of knowledge. The statistical tests of differences between experimental group of students who used the virtual laboratory and the control group of students who were taught according to the traditional way of teaching, confirmed three hypotheses and rejected one hypothesis. The unjustified hypothesis was the one concerning the reproduction of the experimental group students' knowledge. The basic empirical findings are:

- We identified statistically significant positive impact on science and knowledge at a higher level of knowledge of the experimental group which was taught the themes Substances, their properties and changes and Pure substances and mixtures using a virtual laboratory.

- With the reproduction of knowledge the difference between the adjusted arithmetic mean of the students' test scores of experimental and control group was not statistically significant $(\mathrm{F}=0.712, \mathrm{P}=0.405)$.

- In measuring the comprehension of knowledge we found the experimental group students' performance was better than of control group students' performance. The difference between the adjusted arithmetic mean is statistically significant $(\mathrm{F}=6.987, \mathrm{P}=0.012)$.

- It turned out that in the application of knowledge that the experimental group gained more knowledge in comparison to the control group as there is a statistically significant difference between the adjusted arithmetic mean ( $\mathrm{F}$ $=26.096, \mathrm{P}=0.000$ ).

Virtual laboratory facilitates laboratory work which sometimes cannot be implemented due to physical or other reasons. Using ICT makes science popular among young people. Retaining knowledge through virtual laboratory has proved to be effective in comparison to traditional lessons in terms of knowledge.

The didactic experiment results based on a relatively small, pilot sample of students have confirmed that the method of using a virtual laboratory potentially has efficient and posi- 
tive impact on students' knowledge. The results encouraged us to upgrade the research in the future with (1) bigger sample across several schools, (2) methodology that will diminish the effect of the teacher/researcher on the knowledge of the pupils and (3) potential international verification.

\section{Literature}

Abdulwahed, M. \& Nagy, Z. (2009). Applying Kolb's Experiential Learning Cycle for Laboratory Education. Journal of Engineering Education, 98 (3): 283-293. Retrieved March 5, 2012, from http://www.jee.org/2009/july/7.pdf

Anderson, T. (2007). The Theory and practice of online learning. Athabasca University: AU Press.

Barke, H. D. \& Wirbs, H. (2002). Structural units and chemical formulae. Chemistry Education: Research and Practice in Europe, 3 (2): 185-200. Retrieved March 5, 2012, from http://www.jee. org/2009/july/7.pdf

Chin, K. L. (1999). The development of Web-based teaching system for engineering education. Engineering Science and Education Journal, 3 (8): 115-118. DOI: 10.1049/esej:19990304

Dalgarno, B. \& Lee, J. W. M. (2010). What are the learning affordances of 3-D virtual environments? British Journal of Educational Techonology, 41 (1): 10-32. DOI: 10.1111/j.14678535.2009.01038.x

Devetak, I., Vogrinc, J. \& Glažar, S. A. (2009). Assesing 16-year old students' understanding of aqueous solution on at submicroscopic level. Research in Science Education, 39 (2): 157-179. DOI: 10.1007/s11165-007-9077-2

Georgiou, J., Dimitropoulos, K. \& Manitsaris, A. (2007). A Virtual Reality Laboratory for Distance Education in Chemistry. International Journal of Social Sciences, 2 (1): 306-313. Retrieved March 5, 2012, from http://www.waset.org/journals/ ijshs/v1/v1-56.pdf

Grimaldi, D. \& Rapuano, S. (2009). Hardware and software to design virtual laboratory for education in instrumentation and measurement. Measurement, 42 (4): 485-493. DOI: 10.1016/j.measurement.2008.09.003

Johnstone, A., H. (1991). Why is science difficult to learn: Things are seldom what they seem. Journal of Computer Assisted Learning, 7: 75-83. DOI: 10.1111/j.1365-2729.1991.tb00230.x

Kirschner, P. \& Huisman, W. (1998). »Dry laboratories« in science education; computer based practical work. International
Journal of Science Education, 20 (6): 665-682, DOI: 10.1080/0950069980200605

Puhek, M. (2009). Interaktivne računalniške simulacije bioloških laboratorijskih vaj. [Interactive computer simulations of biological laboratory exercises.] Diploma assignment, University of Maribor, Faculty of Natural Science and Mathematics.

Rajendran, L., Veilumuthu, R. \& Divya, J. (2010). A study on the effectiveness of virtual lab in E-learning. International Journal on Computer Science and Engineering, 2 (6): 2173-2175. Retrieved March 5, 2012, from http://www.enggjournals.com/ ijcse/doc/IJCSE10-02-06-91.pdf

Šorgo, A. \& Špernjak, A. (2007). Profesorice bi morale biti zgoraj brez ali kaj spremeniti v pouku biologije. [Professor should be topless or change something in biology class.], Vzgoja in izobraževanje, 38 (5): 37-40.

Šorgo, A., Verčkovnik, T. \& Kocijančič, S. (2007). Laboratorijsko delo pri pouku biologije $\mathrm{v}$ slovenskih srednjih šolah. [Laboratory work in biology teaching at Slovenian secondary schools]. Acta Biologica Slovenica, 50 (2): 113-124.

Sun, K., Lin, Y. \& Yu, C. (2008). A study on learning effect among different learning styles in a Web-based lab of science for elementary school students. Computers \& Education, 50: 14111422. DOI: 10.1016/j.compedu.2007.01.003

Vrtačnik, M., Ferk, V., Fir, M., Dolničar, D., Renič, V., Potisk, B. \& Pozderec, N. (2003). Dinamična vizualizacija naravoslovnih pojmov s poskusi in modeli. [Dynamic visualization of scientific concepts, experiments and models]. Ljubljana: University of Ljubljana, Faculty of Natural Sciences and Engineering.

Zimmerer, C., Thiele, S., Slazer, R., Krauseneck, A. \& Körndle, H. (2003). Internet Teaching: Laboratory Course in Analytical Chemistry. Microchima Acta, 142: 153-159. DOI: 10.1007/ s00604-003-0012-6

Nataša Rizman Herga is a teacher of chemistry and biology in Primary school Ormož. As a postgraduate student of Educational Sciences she conducts researches and publishes in the area of teaching science and e-learning.

Dejan Dinevski is an associate professor at the Faculty of Education and Faculty of Medicine, University of Maribor. He coordinated several international and national projects in the the wider area of e-learning. $\mathrm{He}$ is an author of several publications on e-learning, including scientific articles and books. 